\title{
Priming to Reduce Mand Response Latency
}

\author{
Nadia Misbahuddin and L.L. Mason*
}

Department of Interdisciplinary Learning \& Teaching, University of Texas at San Antonio, USA

\begin{abstract}
This investigation evaluated the effectiveness of a priming intervention to decrease the latency to mand for a five-year-old boy diagnosed with autism spectrum disorder. Parent participation in clinical applied behavior analytic intervention was increased by providing the family members with a home- and community-based priming technique to increase the efficacy of clinical treatment. Using a multiple-baseline design across settings, mand response latency was analyzed as a function of the verbal behavior priming intervention employed by two different caregivers. Results of the study indicate that the caregiver-implemented priming intervention was successful in reducing the child's latency to vocalize a request, allowing for more efficient use of instructional time.
\end{abstract}

Keywords: Autism spectrum disorder, response latency, priming, manding, behavioral momentum.

\section{INTRODUCTION}

Priming is an antecedent intervention designed to prepare an individual to effectively perform a task or activity. Educational priming often involves presenting a learner with an opportunity to preview a task or activity prior to its occurrence [1]. Presently, there is a dearth of research on priming as an educational tool. Priming has been addressed in research for memory retrieval, stimulus processing, mood states, composition, ethics, and social interactions [1], but has not been thoroughly investigated as an effective tool to increase functional communication, including the ability to mand, or request access to favorite items and activities within the instructional setting.

Priming has been found effective for increasing a variety of pro-social and academic skills for children with autism. Video priming has been shown to be effective to increase staying dry during toilet training [1]. Based on the procedures developed by Wilde, Koegel, and Koegel [2], the child viewed the 'potty' video immediately prior to being prompted to go to the bathroom. The priming of the bathroom procedures prior to the actual bathroom demand increased the child's ability to remain dry.

Similarly, video priming had been used to reduce disruptive behavior during transitions with children with autism. In a study by Schreibman, Whalen, and Stahmer [3], three children with autism demonstrated disruptive behaviors during specific transitions. The specific locations of the problematic transitions were videotaped. Using a priming approach, the participants viewed their transition specific videos immediately before partaking in the transition. The study demonstrated a decrease in disruptive behaviors

*Address correspondence to this author at 1 UTSA Cir, San Antonio, TX 78249, USA; Tel: 210-458-4524; E-mail: lee.mason@utsa.edu during the transition as well as a generalization of decrease to other transitions.

Priming has also been found to be effective in training children with autism to make spontaneous initiations to peers. Zanolli, Daggett, and Adams [4] used a priming technique with preschool age children immediately prior to play or social activities. During the priming phase, the children with autism were provided with instructor prompts as they interacted with a typical peer. While in the activity phase, the children were involved in peer interactions but without prompting from the teacher. Priming for social interactions has also been shown to increase spontaneous initiations, including the rate of such initiations [5].

The effects of priming may also be examined as a change in behavioral momentum. Behavioral momentum refers to the tendency for an established response pattern to maintain following a change in environmental conditions [6]. Momentum is a function of the current schedule of reinforcement, and describes the persistence of the behavior subsequent to the delivery of the latest reinforcer. When a series of responses that are strong in the individual's repertoire precede a weaker response, the probability that the weaker response will then be emitted is increased. A high-probability (high-p) command sequence thus strengthens the control over low-probability (low-p) responses.

In the presence of distractions, the persistence of behavior provides an appropriate measure of the strength of behavior. Mace et al. [6] found that high-p command sequences were effective for reducing task avoidance and latency, as well as reducing duration to completion of self-care routines for individuals with severe intellectual disabilities. Other researchers have found the systematic interspersion of high- and low-p tasks effective for strengthening other behaviors such 
as academics [7-10], feeding [11], social interactions [12], and transitions from highly preferred to less preferred activities [13].

Little research has been conducted to assess the effects of high-p command sequences on low-p verbal operants. Volkert, Lerman, Trosclair, Addison, and Kodak [14] examined the effects of similar versus dissimilar interspersed tasks while teaching children with autism and developmental delays to tact pictures of common objects. However, results showed no benefit to interspersing high-p tacts with low- $p$ tacts when highly preferred reinforcers were provided for correct unknown object labels.

Similarly, Rowan and Pear [15] compared the use of a high-p command sequence to a concurrent training sequence for strengthening the tacts of three children with intellectual disabilities. Participants learned to identify pictures of objects more rapidly under the highp command sequence. However, maintenance probes showed no consistent difference between the two procedures in percentage of learned picture names retained, and tacts acquired in both conditions generalized equally across settings, testers, and to the actual objects depicted in the pictures.

While the high-p command sequence appears to be appropriate for expediting the acquisition of novel verbal responses, the evidence for such practices are limited to the tacting repertoire. As a priming tool, high$p$ command sequences may be highly effective for strengthening other verbal operants. Additionally, high$p$ priming sequences are typically implemented by trained researchers or skilled behavior analysts. The social validity of such an intervention could be drastically increased if it could be employed by the family members of children with special needs. In the current study, we sought to expand the literature base on high-p priming sequences to strengthening mands, a functionally independent operant class. Two relatives of a child with an autism spectrum disorder implemented the high-p priming sequence. Following Mace and colleagues' [6] use of response latency as a primary dependent variable, we examined the extent to which a high-p priming sequence would decrease the latency to mand for a child with autism.

\section{METHODS}

\section{Participant and Setting}

A five year-old male child, diagnosed with PDDNOS and enrolled in an applied behavior analytic
(ABA) clinic at a local university, participated in this experiment. This participant was selected for the study because he demonstrated a significant delay in manding upon initiation of each therapy session. Although his Verbal Behavior Milestones Assessment and Placement Program (VB-MAPP)[16] profile demonstrated that he was instructional at level two for making requests, Brad consistently demonstrated a significant mand response latency. At the start of each 90-min therapy session, Brad presented a very reserved and quiet demeanor. By the end of the session, he was loud enough to be heard through the closed door to the therapy room, and was frequently emitting a variety of mands. Come the start of the next session, however, he was back to his quiet self. In contrast to his ability to mand, the participant demonstrated an ability to tact at a level three according to his VB-MAPP profile.

\section{Procedures}

The participant received $90 \mathrm{~min}$ of referent-based instruction [17] four days a week. On Mondays and Wednesdays, his aunt brought him to the ABA center, and on Tuesdays and Thursdays his father dropped him off. The dependent variables were mand response latency prior to Brad emitting a mand. Our intervention involved a high-p priming procedure prior to beginning each therapy session. Using a multiple baseline design, the effects of the intervention were assessed across both Brad's aunt and dad, two primary members of Brad's verbal community.

\section{Baseline}

Throughout the baseline condition, Brad's teacher (first author) greeted the participant in the waiting room and presented a coloring worksheet (a previously identified reinforcer), while a box of crayons was visible but inaccessible to the participant. A second observer recorded mand response latency by running a stopwatch from the time from which the teacher entered the waiting room to the moment that Brad emitted a mand. This observer also counted the frequency of verbalizations that Brad emitted until his first mand. Brad's individualized treatment plan was carried out in the waiting room until he emitted the first mand of the session, at which point the reinforcer he selected was provided and Brad was brought back to the therapy room.

During the baseline condition, caregivers were not asked to restrict the amount of verbal responses in 
which they engaged Brad. Rather, we collected baseline data without informing the caregivers of their involvement in the study to minimize reactivity, and provide a more valid assessment of baseline levels. The onset of the intervention was staggered across Brad's aunt and father. The aunt, who began treatment first, was explicitly told not to share the priming procedure with the father, and she verbally committed to doing so.

\section{Priming}

The priming condition was identical to the baseline condition, except that Brad's caregivers were instructed to use high-p priming techniques from the moment they picked up Brad from school until the start of $A B A$ therapy. Brad's dad and aunt were given a list of sample questions and verbal prompts designed to evoke verbal responses from Brad. The caregivers were asked to solicit a verbal response from Brad at least once a min.

To control the methods of priming used across both interveners, Brad's aunt and father, a list of sample questions was given to both caregivers (e.g., "What did you do at school today?"). The teacher also modeled priming questions and statements with each caregiver at the corresponding point of intervention, and provided daily reminders via notes to take home or verbal directions for the priming to occur. Additionally, when the teacher observed a reduction from mean baseline level in latency before a mand was made, she provided verbal praise to the guardian for implementing the priming procedure.

\section{Interobserver Agreement}

Interobserver agreement data was collected for $56 \%$ of all sessions, across both low-p and priming conditions. Agreement averaged $95 \%$, and ranged from $64 \%-100 \%$. The lowest agreement score, $64 \%$, was achieved on the first day of data collection. Observers were retrained on recording procedures, and, subsequently, the lowest agreement score was $80 \%$.

\section{RESULTS}

In this study we sought to identify the extent to which a high-p priming sequence would reduce the time to mand response latency for a young boy with autism. Figure 1 shows the latency between the time that the $A B A$ therapist entered the waiting room and the time that Brad emitted a mand. Time to mand is shown for sessions prior to the implementation of the priming intervention and during the intervention phase.

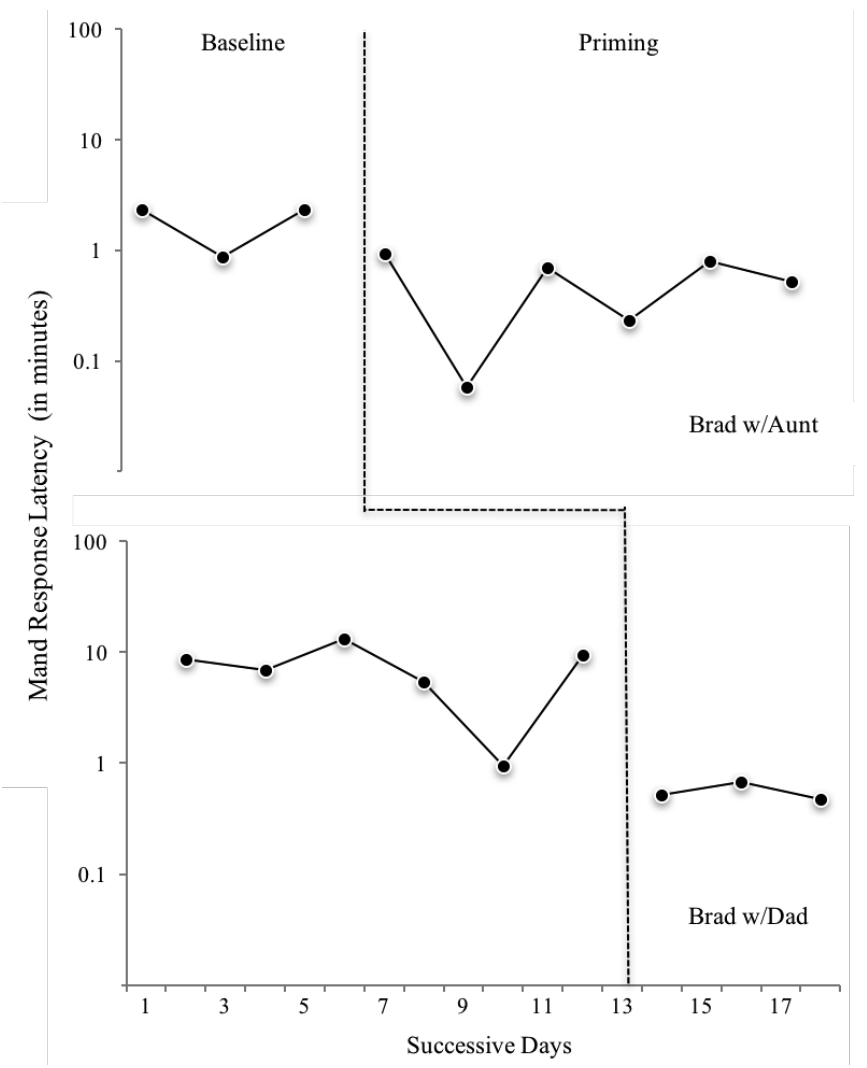

Figure 1: Length of time from the start of the session to Brad's first word when dropped off by his aunt (top) and father (bottom).

During the baseline condition, Brad averaged $1 \mathrm{~min}$ $51 \mathrm{~s}$ to mand when his aunt dropped him off, and $8 \mathrm{~min}$ $39 \mathrm{~s}$ when his dad dropped him off. In the priming condition, latency decreased to an average of $34 \mathrm{~s}$ with his aunt, and $30 \mathrm{~s}$ with his father. The data show slight overlap between Low-p and the first datum in High-p for Brad with his aunt. The data are divided beyond this, however, as well as across both phases for Brad with his dad.

The present study sought to investigate the efficacy of a parent implemented high-p priming procedure to decrease the latency to mand when entering the educational setting. It was hypothesized that a high-p priming sequence prior to clinical sessions would decrease the latency to mand upon entering the clinic waiting room. Consistent with prior research, our data suggests that a high-p command sequence immediately prior to a low-p response decreases the response latency $[1,5,6]$.

Although there is an overlap in data during low-p and high-p phases, overall the high-p phases indicate a 
clear decrease in mand response latency as a result of caregiver priming. The results for priming implemented by Brad's father indicate that during Day 9 of the low-p phase, Brad emitted a mand in less than one min after being greeted by his teacher. Records indicate that on this day, Brad and his father had arrived approximately five min early and engaged in conversation while in the waiting room before the session began. The conversation included questions and comments about therapy and related activities, and likely contributed to the reduced mand response latency for this particular session.

Overall results indicate a significant decrease in latency to mand when his father implemented the priming procedure. Excluding Day 9, Brad's time to mand ranged from $13 \mathrm{~min} 08 \mathrm{sec}$ to $6 \mathrm{~min} 48 \mathrm{~s}$. In the high-p phase, when priming was occurring, Brad's time to mand decreased to a range of $41 \mathrm{~s}$ to $28 \mathrm{~s}$. Multiple min to mand during low-p had significantly decreased to less than one min to mand during high-p.

The results of the study provide several important implications for parental involvement, clinical training, and applied settings. Teachers often provide homework or strategies for parents to use in the home setting. Many times, suggested strategies are not contingent on behavior in the school or clinic setting. It is often at the parent or guardian discretion to utilize strategies, with no way for instructors to verify skill implementation outside of the instructional environment. For example, a suggestion to practice addition at home will not inform the teacher of the effect it may have on the child's ability to add during subsequent instructional sessions. Providing high-p commands immediately prior to an instructional setting can result in a correlated effect to the child's response behavior. As low-p responses increase, the teacher can praise guardians for implementation of the high-p priming procedure, therefore maintaining or increasing parental involvement in the learning process. Additionally, as low-p responses are strengthened to high-p responses, they may further be used to evoke other low- $p$ responses.

\section{DISCUSSION}

Consistent with other research on social skills priming $[1,5]$, the results of this study show that the use of high-p commands as a priming intervention may help maximize instructional training sessions. The present research extends the literature base on priming to the domain of verbal behavior instruction. Presenting a high-p priming sequence prior to an instructional session provides behavioral momentum to increase the strength of low-p responses, thereby maximizing the efficiency of a time-limited intervention session. Including caregivers as part of the intervention procedures therefore directly benefits the teacher as well.

Limitations to the current study include only two points of comparison for examining the effectiveness of the low-p priming sequence. A stronger experimental design, such as reversing to the baseline phase or including a third guardian in the treatment phase, could have provided additional points of effects for this study. Inclusion of multiple participants could have also provided further points of effect to strengthen the findings of the study. However, due to the nature of the setting and availability of participants, only one participant was appropriate for this study.

Limitations also existed within the data collection, as the teacher/researcher was not blind to the study parameters. Moreover, our procedures did not allow us to accurately assess the fidelity of the priming intervention. Future studies should include more a rigorous system for data collection, fidelity procedures, and a treatment design that includes multiple points of effect.

It is important to note that mands are definitionally under the control of both the motivation of the speaker and the presence of a listener. The current study in no way attempted to manipulate motivating operations; rather, the context for producing any vocal speech was manipulated through the priming procedure. Since it is impossible to physically prompt verbal behavior, other antecedent strategies must suffice to induce speech when it has not come under the relevant properties of stimulus control (e.g., the presence of a listener). As displayed in the current study, however, priming appears to be an effective method of conditioning the presence of a teacher to reinforce the verbal behavior of a young child with autism.

\section{CONFLICT OF INTEREST}

The authors do not report any conflict of interest.

\section{REFERENCES}

[1] Gengoux GW. Priming for social activities: Effects on interactions between children with autism and typically developing peers. Journal of Positive Behavior Interventions 2015; 17(3): 181-192.

https://doi.org/10.1177/1098300714561862 
[2] Wilde L, Koegel L, Koegel R. Increasing success in school through priming: A training manual. 1st ed. Santa Barbara, CA: University of California 1992.

[3] Schreibman L, Whalen C, Stahmer A. The use of video priming to reduce disruptive transition behavior in children with autism. Journal of Positive Behavior Interventions 2000; 2(1): 3-11. https://doi.org/10.1177/109830070000200102

[4] Zanolli K, Daggett J, Adams T. Teaching preschool age autistic children to make spontaneous initiations to peers using priming. Journal of Autism and Developmental Disorders 1996; 26(4): 407-422. https://doi.org/10.1007/BF02172826

[5] Cihak DF, Smith CC, Cornett A, Coleman M. The use of video modeling with the picture exchange communication system to increase independent communicative initiations in preschoolers with autism and developmental delays. Focus on Autism And Other Developmental Disabilities 2012; 27(1): 3-11. https://doi.org/10.1177/1088357611428426

[6] Mace F, Hock M, Lalli J, West B, Belfiore P, Pinter E, et al. Behavioral momentum in the treatment of noncompliance. Journal of Applied Behavior Analysis 1988; 21(2): 123-141. https://doi.org/10.1901/jaba.1988.21-123

[7] Browder D, Shear S. Interspersal of known items in a treatment package to teach sight words to students with behavior disorders. The Journal of Special Education 1996; 29(4): $400-413$ https://doi.org/10.1177/002246699602900403

[8] Dunlap G. The influence of task variation and maintenance tasks on the learning and affect of autistic children. Journal of Experimental Child Psychology 1984; 37(1): 41-64. https://doi.org/10.1016/0022-0965(84)90057-2

[9] Neef N, Iwata B, Page T. The effects of known-item interspersal on acquisition and retention of spelling and sightreading words. Journal of Applied Behavior Analysis 1977; 10(4): 738-738.

https://doi.org/10.1901/jaba.1977.10-738
[10] Neef N, Iwata B, Page T. The effects of interspersal training versus high-density reinforcement on spelling acquisition and retention. Journal of Applied Behavior Analysis 1980; 13(1): 153-158. https://doi.org/10.1901/jaba.1980.13-153

[11] Patel M, Reed G, Piazza C, Bachmeyer M, Layer S, Pabico R. An evaluation of a high-probability instructional sequence to increase acceptance of food and decrease inappropriate behavior in children with pediatric feeding disorders. Research in Developmental Disabilities 2006; 27(4): 430442. https://doi.org/10.1016/j.ridd.2005.05.005

[12] Davis C, Brady M, Hamilton R, McEvoy M, Williams R. Effects of high-probability requests on the social interactions of young children with severe disabilities. Journal of Applied Behavior Analysis 1994; 27(4): 619-637. https://doi.org/10.1901/jaba.1994.27-619

[13] Singer G, Singer J, Horner R. Using pretask requests to increase the probability of compliance for students with severe disabilities. Research and Practice for Persons with Severe Disabilities 1987; 12(4): 287-291. https://doi.org/10.1177/154079698701200405

[14] Volkert V, Lerman D, Trosclair N, Addison L, Kodak T. An exploratory analysis of task-interspersal procedures while teaching object labels to children with autism. Journal of Applied Behavior Analysis 2008; 41(3): 335-350. https://doi.org/10.1901/jaba.2008.41-335

[15] Rowan V, Pear J. A comparison of the effects of interspersa and concurrent training sequences on acquisition, retention, and generalization of picture names. Applied Research in Mental Retardation 1985; 6(2): 127-145. https://doi.org/10.1016/S0270-3092(85)80066-7

[16] Sundberg M. Verbal behavior milestones assessment and placement program: The VB-MAPP. 1st ed. Concord, CA. AVB Press; 2008.

[17] Mason LL, Andrews A. Referent-based verbal behavior instruction for children with autism. Behavior Analysis in Practice 2014; 7(2): 107-111. https://doi.org/10.1007/s40617-014-0018-z

\section{DOI: https://doi.org/10.6000/2292-2598.2017.05.02.1}

(C) 2017 Misbahuddin and Mason; Licensee Lifescience Global.

This is an open access article licensed under the terms of the Creative Commons Attribution Non-Commercial License (http://creativecommons.org/licenses/by-nc/3.0/) which permits unrestricted, non-commercial use, distribution and reproduction in any medium, provided the work is properly cited. 